\title{
DIAGNÓSTICO DAS TEMÁTICAS SUGERIDAS PELOS PROFESSORES DE GEOGRAFIA E HISTÓRIA DA EDUCAÇÃO BÁSICA PARA ELABORAÇÃO DE MATERIAIS DIDÁTICOS - PEDAGÓGICOS SOBRE FEIRA DE SANTANA
}

\author{
Edson da Silva Santos ${ }^{1}$; Célia Regina Batista dos Santos ${ }^{2}$ \\ 1. Bolsista PIBIC/CNPq, Licenciado em Geografia e estudante de Bacharelado em Geografia, Universidade Estadual de Feira \\ de Santana, e-mail: edsonsporte@ hotmail.com \\ 2. Orientadora, Departamento de Educação, Universidade Estadual de Feira de Santana, e-mail: \\ celia_regina2006@hotmail.com
}

PALAVRAS-CHAVE: Prática docente; Material didático; Lugar Feira de Santana.

\section{INTRODUÇÃO}

Os materiais didáticos, dentre outros objetivos, são utilizados no processo de ensinoaprendizagem com o intuito de facilitar a mediação pedagógica, tornar as aulas mais atraentes, dinâmicas e significativas, tanto para os educandos, quanto para os educadores. Diante disso, por material didático entende-se "todo e qualquer recurso utilizado em um procedimento de ensino, visando à estimulação do aluno e à sua aproximação do conteúdo" (FREITAS, 2007, p. 21). Todavia, a carência de material didático que contemple a escala local é uma realidade marcante em muitas cidades brasileiras. Tal constatação toma como exemplo os livros didáticos, material amplamente utilizado em muitas escolas brasileiras, por vezes distribuídos gratuitamente em instituições públicas de ensino, produzidos em sua maioria no eixo sulsudeste do Brasil e abordam geralmente temáticas dos locais de produção, assim como centros dinâmicos e/ou de maior relevância no cenário nacional.

Essa política, por vezes vista como algo implantado verticalmente, implica em aulas descontextualizadas que colaboram para o desconhecimento de problemas e potencialidades locais, por parte dos educandos, contribuindo muitas vezes para a sua não identificação e consequentemente não intervenção crítica em seu lugar de vivência, haja vista, estudam realidades distantes. Entretanto, ressalta-se que é impossível e até mesmo utópico contemplar todos os lugares em um livro didático, ainda mais em um país de dimensões continentais como o Brasil. Não obstante, esse alerta se faz necessário e tem por objetivo chamar atenção dos órgãos competentes para que estimulem a produção de livros e materiais didáticos capazes de abordar em seus conteúdos a escalas local e regional das cidades onde são distribuídos (D’AVILA, 2008).

A cidade de Feira de Santana é um desses lugares não contemplados nos livros didáticos utilizados nas escolas feirenses e nossos estudos vêm indicando que muitos professores possuem dificuldade em mediar o conhecimento do conteúdo oficial com a realidade local. Assim, no sentido de minimizar essa situação, com o intuído de diversificar a utilização de material didático no ambiente escolar e tonar as aulas mais contextualizadas com a realidade local; e acreditando e valorizando a capacidade dos professores em produzirem conhecimentos através da pesquisa-ação-reflexão de sua prática pedagógica no ambiente escolar onde atuam (PIMENTA,1997) é que a presente pesquisa pretendeu investigar a opinião dos professores sobre o ensino de Feira de Santana nas aulas de história e geografia e se eles fazem esse tipo de abordagem; identificar como os professores correlacionam o conteúdo do currículo oficial ao ensino/estudo da escala local (Feira de Santana); diagnosticar quais temáticas são sugeridas pelos professores investigados para nortearem a elaboração de material didático/pedagógico sobre a cidade de Feira de Santana; e avaliar se as temáticas sugeridas pelos professores são exequíveis para serem contempladas nos materiais a serem elaborados pelo grupo de pesquisa. 


\section{METODOLOGIA}

A presente investigação possui caráter colaborativo e intervencionista- e engajou-se nos contornos da pesquisa qualitativa (BOGDAN E BIKLEN, 1994) pela necessidade de valorizar a reflexão sobre a ação, a problematização, as experiências dos sujeitos envolvidos. Seu desenvolvimento ocorreu a partir de quatro momentos, a saber: o primeiro momento norteou-se por estudos teóricos dos conceitos-chaves da pesquisa. No segundo momento, produziu-se e testou-se um roteiro de entrevista composto por 11 questões abertas, utilizado, na produção dos dados primários. Já o terceiro momento destinou-se a realização de trabalho de campo com visitação a três escolas públicas da rede estadual de ensino do Estado da Bahia, situadas na cidade de Feira de Santana, e entrevistou-se 12 docentes, seis que lecionam a matéria Geografia e seis que lecionam a matéria História e contou com o auxílio de um gravador, cujas falas dos (as) entrevistos (as) foram registradas e transcritas pelos pesquisadores da mesma forma como foram ditas.

As entrevistas iniciaram-se no mês de fevereiro de 2016 e encerraram-se em julho do mesmo ano, totalizando nove encontros. Vale frisar que, durante as gravações, no momento em que o entrevistado estava falando, a interrupção do entrevistador ocorria apenas para realizar outros questionamentos ou solicitar esclarecimentos. Optou-se pela realização de entrevistas pela necessidade de uma compreensão mais detalhada do objeto em estudo (GASKELL, 2003). Logo, a análise do corpus textual das entrevistas pautou-se nos princípios da análise de conteúdo, processo que segundo Bardin, (1977), envolve pré-análise, exploração do material, tratamento dos resultados, inferência e interpretação. Por fim, no quarto momento as falas transcritas foram analisadas, à luz da bibliografia consultada. Vale ressaltar que, os docentes foram selecionados previamente e constituem-se parceiros na produção, teste, avaliação e futuras publicações dos materiais produzidos. Aceitaram participar de forma espontânea da pesquisa, permitiram a gravação, assim como foram avisados que seus dados pessoais e da instituição, por questões éticas, seriam salvaguardados.

\section{RESULTADOS E/OU DISCUSSÃO}

No contexto atual, o estudo e ensino de Lugar tem sido compreendido, como um laboratório para se compreender o mundo, assim como tornar o processo de ensino e aprendizagem mais significativo, ao passo que contribui para o processo de formação e/ou (re)afirmação da(s) identidade(s) das pessoas para com o seu lugar de vivência. Diante dessas atribuições buscou-se saber dos docentes de História e de Geografia qual importância atribuem ao estudo de lugar Feira de Santana em sala de aula. Tal inquietação pauta-se no entendimento de que o estudo da escala local, o bairro, a cidade o município, sempre articulado com a escala global respaldada numa mediação pedagógica crítica que tenha o educando enquanto sujeito ativo de todo processo de ensino e aprendizagem, o possibilita conhecer sua realidade, problemas e potencialidades e nela intervir de forma consciente (LIMA e TOMAZ, 2007).

As respostas para tal inquietude, segundo os docentes, consistem em tornar o ensino mais fácil e significativo, bem como contribui para que o discente compreenda seu local. Nesse sentido, observa-se que os docentes preocupam-se com o processo de ensinoaprendizagem contextualizado com a realidade local dos educandos para facilitar a aprendizagem e possibilitar meios para compreender o local, ao passo que pretendem tornar o ensino mais significativo.

Face ao exposto, investigou-se se os docentes costumam utilizar a cidade e/ou município de Feira de Santana nas aulas de História e de Geografia. E se caso utilizam, se sua abordagem é como conteúdo programático ou apenas como exemplo. Como resposta, todos os investigados, responderam que sim, porém apenas quatro, utilizam enquanto conteúdo programático. Os demais, no caso oito dos 12 entrevistados utilizam a cidade e/ou município 
apenas a titulo de exemplo. No entanto, é importante que não somente exemplifique e/ou enumere determinado conteúdo da temática em estudo, mas sim o problematize, ainda mais quando se trata da realidade local, na qual a formação da consciência crítica é tão necessária.

Muito embora utilizem a cidade e/ou município de Feira de Santana como exemplo e/ou como conteúdo programático, essa pesquisa teve como inquietação saber dos professores quais seriam as principais dificuldades encontradas para mediar o conteúdo com a escala local. Para tal indagação, apenas um professor afirmou não ter dificuldade, porém não explicou o porquê. Os outros 10 (dez) professores justificaram como principal dificuldade a falta de material didático que contemple temáticas locais. Todavia, não menos importante, citado por um dos investigados, encontra-se a questão de ter propriedade teórica para trabalhar com a realidade local. Essas constatações inspiram mudanças de imediato sobre a pena de prejudicar o conhecimento histórico espacial dos estudantes, fundamental para sua autonomia enquanto cidadão.

Diante disso, tivemos a preocupação em saber quais temáticas referentes à Feira de Santana os professores de História e Geografia da escola básica, gostariam que fossem abordadas em um material didático, assim como convidá-los para participarem da elaboração. Essa iniciativa pautou-se no entendimento de que os professores, devido a sua experiência cotidiana de ensino na escola básica, apresentam valiosas contribuições para o material didático que se pretende elaborar no âmbito do grupo de pesquisas, principalmente porque possuem maior percepção, tanto das suas necessidades, quanto das necessidades dos alunos (PEDRA, 2008).

A resposta para a preocupação supramencionada obteve 40 temáticas, destas, 20 fornecidas pelos docentes da matéria geografia e 20 da matéria de história. Trata-se de temáticas que envolvem desde temas intrínsecos ao conteúdo oficial da disciplina até conteúdos interdisciplinares, como os temas transversais. Contudo, precisou-se eleger as que foram consideradas importantes em temos de conteúdo e custo financeiro, para que sejam comtempladas com a produção de material didático por integrantes do Grupo Lugar ${ }^{1}$. Dessa forma, os materiais didáticos poderão ser elaborados em forma de textos, imagens, ou como melhor for decidido pelos integrantes do referido grupo. Levando-se em consideração esses aspectos supracitados, a princípio, apenas serão contempladas 14 temáticas, destas, sete indicadas por docentes de história e sete indicadas por docentes de Geografia, como pode ser observado no Quadro 1.

Quadro 1 - Temáticas selecionadas para a produção de material didático no âmbito
do grupo de pesquisa e estudo Lugar Temáticas
\begin{tabular}{|c|c|}
\hline Professores de História & Professores de Geografia \\
\hline $\begin{array}{c}\text { Memórias do patrimônio urbano de Feira } \\
\text { de Santana. }\end{array}$ & Feira Livre \\
\hline $\begin{array}{c}\text { História do surgimento da cidade de Feira } \\
\text { de Santana }\end{array}$ & $\begin{array}{c}\text { Agricultura Familiar no município } \\
\text { de Feira de Santana }\end{array}$ \\
\hline $\begin{array}{c}\text { História dos Bairros de Feira de } \\
\text { Santana }\end{array}$ & $\begin{array}{c}\text { Maquetes do relevo de Feira de } \\
\text { Santana }\end{array}$ \\
\hline $\begin{array}{c}\text { História das festas populares de } \\
\text { Feira de Santana }\end{array}$ & $\begin{array}{c}\text { Maquete de bacias hidrográficas } \\
\text { de Feira de Santana }\end{array}$ \\
\hline $\begin{array}{c}\text { Aspectos culturais de Feira de } \\
\text { Santana }\end{array}$ & Mapa temático da área urbana \\
\hline $\begin{array}{c}\text { Resgate da identidade história e } \\
\text { social da população feirense }\end{array}$ & $\begin{array}{c}\text { Mapa de uso e ocupação do solo } \\
\text { do Município de Feira de Santana }\end{array}$ \\
\hline
\end{tabular}

${ }^{1}$ Grupo de estudos e pesquisas formado por docentes da escola, básica, licenciados e docentes Universidade Estadual de Feira de Santana. 


\begin{tabular}{|c|r|}
\hline $\begin{array}{c}\text { Mapas antigos e atuais de Feira de } \\
\text { Santana }\end{array}$ & Solos de Feira de Santana \\
\hline
\end{tabular}

Ao analisar as temáticas fornecidas pelos docentes observa-se que contemplam tanto temas históricos e atuais, como temas referentes à produção do espaço através das relações humanas estabelecidas socioespacialmente.

\section{CONSIDERAÇÕES FINAIS}

Os dados obtidos indicam que os docentes de História e Geografia das escolas investigadas abordam a cidade de Feira de Santana em sala de aula e consideram importante esse tipo de abordagem, pois contribui para que os discentes compreendam as relações que se estabelecem no cotidiano. Todavia, esbarram na carência de material didático e de conhecimento teórico metodológico que contemple a realidade local. Dessa forma, utilizam a cidade e/ou município de Feira de Santana apenas para realizar exemplos em sala de aula durante a mediação pedagógica de um conteúdo. Abordar o local de vivência em sala de aula apenas citando como exemplo resulta numa aprendizagem limitada, pois acredita-se que o objetivo da educação está para além da simples exemplificação, descrições ou enumerações. Deve pautar-se, principalmente, em problematizações, pois almeja-se desenvolver sujeitos críticos, autônomos e atuantes para que se tenha uma sociedade mais justa. A superação dessa limitação é imprescindível sob pena de um ensino não condizente com o contexto atual. Nesse sentido, a produção de material didático a partir de temáticas fornecidas pelos professores, apresenta-se como importante método a ser adotado.

\section{REFERÊNCIAS}

BARDIN, L. Análise de Conteúdo. Lisboa, Lisboa: Edições 70, 1977.

BOGDAN, R.; BIKLE, S. Investigação qualitativa em educação: uma introdução à teoria e aos métodos. Porto: Porto Editora, 1994.

D'AVILA, C. Decifra-me ou te devorarei: o que pode um professor frete a um livro didático? 1. ed. Salvador: EDUNEB; EDUFBA, 2008.

FREITAS, O. Equipamentos e materiais didáticos. Brasília: Editora UnB, 2007.

GASKELL, G. Entrevistas individuais e grupais. In: __. BAUER, Martin W; GASKELL, George (Org). Pesquisa qualitativa com texto, imagem e som: um manual prático. 2. ed. Tradução de Pedrinho Arcides Guareschi. Petrópolis. RJ: Vozes, 2002. Pat, pp 64 - 89.

LIMA, J. A.; THOMAZ, S. L. O estudo do lugar e a formação do aluno cidadão. UEM, 2007. Disponível em:.< http://www.gestaoescolar.diaadia.pr.gov.br/modules/conteudo/conteú do.php?conteudo=129>. Acesso em: 05 de jun. 2016.

PEDRA, M. O. M. Ensinado Geografia a partir do local: relato de experiências de ensino aprendizagem vivenciadas em turmas de sétimas séries. Londrina (Pr). 2008. Disponível em:. <http://www.diaadiaeducacao.pr.gov.br/portals/pde/arquivos/388-4.pdf>. Acesso em 03 nov. 2011.

PIMENTA, S. G. Formação de professores: saberes da docência e identidade do professor. Nuances: estudos sobre Educação, v. 3, n. 3, pp. 5-14, set. 1997. 